\title{
FORMAÇÃO, RELACIONADA À GESTÃO, OFERECIDA EM CURSOS DE GRADUAÇÃO EM EDUCAÇÃO FÍSICA: UM OLHAR QUALITATIVO SOBRE CURRÍCULOS, DISCIPLINAS E EMENTAS
}

\author{
Alfredo Ribeiro Cárdenas \\ Universidade do Estado de Santa Catarina, Florianópolis, Santa Catarina, Brasil \\ Simone Ghisi Feuerschütte \\ Universidade do Estado de Santa Catarina, Florianópolis, Santa Catarina, Brasil
}

\begin{abstract}
Resumo
O objetivo deste estudo, qualitativo e descritivo, foi analisar a formação, relacionada à gestão, oferecida em cursos de graduação em Educação Física. Foi realizada análise documental de currículos, disciplinas e ementas das disciplinas relacionadas à gestão, dos cursos de bacharelado da área no estado de Santa Catarina. Os resultados apontam categorias temáticas identificadas nas disciplinas e ementas, e demonstram que a formação se apresenta de maneira heterogênea nos cursos investigados. Concluiu-se que os conteúdos de gestão são importantes para a formação em Educação Física e que instituições de ensino devem considerar tais conteúdos como componentes fundamentais da formação, visto ser a gestão do esporte uma possibilidade de intervenção do futuro profissional da área.
\end{abstract}

Palavras-chave: Formação. Gestor esportivo. Gestão do esporte. Educação Física.

\section{1- Introdução}

Os profissionais de Educação Física são comumente reconhecidos como especialistas em questões relativas aos esportes e aos exercícios físicos (CONFEF, 2002). Não é difícil, afinal, encontrar tais profissionais ministrando a disciplina em uma escola ou instruindo em academias de ginástica. Existem, no entanto, outras especificidades, pouco ou menos conhecidas, de intervenção do profissional de Educação Física.

Nesse sentido, há mais de dez anos o Conselho Federal de Educação Física (CONFEF) apresentou à sociedade brasileira o documento intitulado "Documento de intervenção do profissional de Educação Física", que esclarece sobre a intervenção dos referidos profissionais. Nele são apontadas as capacidades necessárias para atuação, as responsabilidades, os locais de atuação, os meios de intervenção, entre outros esclarecimentos sobre a atuação do profissional em questão (CONFEF, 2002).

No referido documento, a gestão do esporte ou, mais especificamente, a "gestão em educação física e desporto" (CONFEF, 2002, p.1) é apontada como uma das sete especificidades da intervenção do profissional em Educação Física. Assim, desde 2002, a "administração e/ou gerenciamento de instituições, entidades, órgãos e pessoas jurídicas cujas atividades fins sejam atividades físicas e/ou desportivas" é declarada como uma das 
possibilidades de atuação de profissionais formados nessa área, no Brasil (CONFEF, 2002, p.1).

Diante de estudos que confirmam que profissionais de Educação Física são, frequentemente, encontrados em cargos administrativos em organizações esportivas brasileiras (AZEVÊDO; BARROS, 2004; BASTOS et al., 2006; MACIEL, 2009; MARONI; MENDES; BASTOS, 2010) e, por outro lado, estudiosos e pesquisadores que convergem na opinião de que a atuação profisssional, nessa área, ainda é bastante incipiente no país (CAPINUSSÚ, 2002; BASTOS, 2003; AZEVÊDO; BARROS; SUAIDEN, 2004; COSTA; MARINHO, 2005;VALENTE; SERAFIM, 2006; VIEIRA; STUCCHI, 2007; AZEVÊDO, 2009; BASTOS;MAZZEI, 2012), Bastos et al. (2006) enfatizam que a melhoria da gestão esportiva brasileira está atrelada ao aperfeiçoamento dos cursos de formação em Educação Física/Esportes, sobretudo, no que diz respeito a formação relacionada à gestão.

Cabe mencionar que, sabidamente, cursos de Educação Física não formam gestores esportivos (formam profissionais de Educação Física), mas a gestão - do esporte - é uma possibilidade de atuação do futuro profissional.

Nesse sentido, pesquisas têm relatado que o conhecimento em gestão tem ganhado espaço nas grades curriculares dos cursos de formação em Educação Física (OLIVEIRA, 2008; BENFICA, 2011; MONTAGNER; SCAGLIA; AMAYA, 2012), indicando uma gradativa ampliação do corpo de disciplinas relacionadas à gestão na formação dos futuros profissionais da área. De acordo com Montagner, Scaglia e Amaya (2012),

[...] estamos deixando de apenas formar profissionais para ensinar esportes dentro das quadras e campos, [...] para também formar gerações com vistas a administrar o esporte, a influenciar nesse importante fenômeno dos séculos XX e XXI, com atuação profissionalizada e atenta às diferentes concepções de gestão e administração (MONTAGNER; SCAGLIA; AMAYA, 2012, p.611).

Realizadas sobre uma perspectiva quantitativa, as referidas pesquisas revelam que conteúdos relacionados à gestão têm sido contemplados na formação em Educação Física e que essa formação apresenta-se de maneira heterogênea em diversas instituições de ensino superior (IES). Observam-se desde cursos oferecendo, em certos casos,disciplinas isoladas - como administração esportiva ou marketing esportivo - até, em outros casos, eixos curriculares completos, incluindo estágios no campo da gestão do esporte.

Resta, porém, a possibilidade de a formação ser investigada sob a luz de uma abordagem qualitativa, o que pode proporcionar resultados que suportem ou contradigam as conclusões já estabelecidas.

Alinhado aos entendimentos e argumentos encadeados até aqui, e considerando, ainda, que a formação é um objeto de estudo que pode ser investigado sob a luz de distintas perspectivas, este artigo teve como objetivo analisar a formação, relacionada à gestão, oferecida em cursos de graduação em Educação Física.

Um estudo nessa dimensão poderá oferecer subsídios para melhor entender o processo de formação de profissionais de Educação Física, no tocante à gestão, possibilitando, ainda, compreender especificamente sobre os saberes adquiridos pelos futuros profis- 
sionais da área para a intervenção no campo de atuação da gestão do esporte. Do mesmo modo, o estudo se justifica de modo a entender e orientar práticas curriculares e as competências para a intervenção dos futuros profissionais.

\section{2- Procedimentos metodológicos}

A investigação caracterizou-se como um estudo descritivo (RICHARDSON et al., 2007; GIL, 2008), o qual buscou compreender,sob a luz de uma abordagem qualitativa, a formação, relacionada à gestão, oferecida em cursos de graduação em Educação Física.

Para isso foi realizada análise documental (CELLARD, 2008; GIL, 2008),dos currículos e das ementas das disciplinas relacionadas à gestão, em cursos de graduação em Educação Física. Foram escolhidos como contexto/delimitação da pesquisa os cursos de bacharelado da área, localizados nos limites do estado de Santa Catarina, Região Sul do Brasil.

Com o intuito de identificar os cursos que atendiam aos critérios estabelecidos e que teriam, portanto, seus currículos analisados, acessou-se no sítio eletrônico do Conselho Regional de Educação Física do Estado de Santa Catarina (CREF3/SC) as IES que ofereciam cursos de Educação Física. A pesquisa realizada entre os meses de julho e agosto de 2013 identificou inicialmente 34 cursos de Educação Física sendo oferecidos no estado.

Ao consultar os sites institucionais dos 34 cursos, observou-se que dois deles não eram da habilitação bacharelado, o que diminuiu o número de instituições a serem analisadas para 32.

Metodologicamente, além do exposto até aqui, cabe, ainda, ser mencionado que: 1) um número expressivo das instituições investigadas - 14 das 32 IESs -, embora disponibilizassem as grades curriculares de seus cursos de formação, não apresentavam os ementários das disciplinas que compunham seus currículos, nos respectivos endereços eletrônicos pesquisados; 2) cinco instituições, devido a mudanças curriculares recentes, apresentavam mais de um currículo para o mesmo curso (nesses casos foram analisados os currículos mais recentes); 3) uma das instituições de ensino não apresentava, no site institucional, nem mesmo o currículo do curso oferecido (essa IES não participou da análise).

Objetivamente falando, foram analisadas, portanto, 31 grades curriculares, e os ementários das disciplinas relacionadas à gestão de todos os 17 cursos de bacharelado em Educação Física que ofereciam os dados necessários à pesquisa.

$\mathrm{Na}$ posse dos currículos/disciplinas e ementas dos cursos atendentes aos critérios de inclusão - cursos de bacharelado em Educação Física, presenciais, em Santa Catarina -, realizou-se análise de conteúdo conforme as recomendações de Bardin (2004), nomeadamente a organização da análise, a codificação e a categorização. Identificaram-se, assim, categorias advindas das disciplinas e ementas investigadas.

\section{3- Apresentação dos resultados e discussão}

Os resultados deste estudo estão segmentados em duas partes principais: primeiramente, apresentam-se considerações advindas da observação e análise geral dos currícu- 
los e disciplinas; em seguida apresenta-se o resultado da análise realizada a partir das ementas das disciplinas relacionadas à gestão.

\section{1- Os currículos de Educação Física e as disciplinas de gestão}

A observação inicial dos currículos demonstrou a existência de uma diversidade de nomenclaturas utilizadas pelas instituições de ensino na identificação das disciplinas relacionadas à gestão. Não obstante essa realidade, é perceptível que a diversidade de terminologias empregadas pelas instituições, muitas vezes, buscam significar um mesmo escopo de conhecimentos abrangidos nas matérias acadêmicas.

"Gestão de eventos", "planejamento de eventos" ou "organização de eventos" por exemplo - são denominações de disciplinas identificadas em diferentes currículos de formação, mas que abordam, claramente, um mesmo objeto de estudo - os eventos. Nesse sentido, percebeu-se que termos como esporte, atividade física, Educação Física, desporto, saúde, lazer, assim como Administração, gestão, organização, planejamento, muitas vezes são empregados diversificadamente nas titulações das disciplinas, mas resultam em conotações assemelhadas.

Após a observação dos currículos e identificação das disciplinas concernentes à temática do estudo, identificou-se a existência de cinco tipos principais, ou categorias, de disciplinas relacionadas à área da gestão. As categorias de disciplinas identificadas foram: (1) Gestão Esportiva, (2) Organização de Eventos, (3) Marketing Esportivo, (4) Empreendedorismo e (5) Estágio em Gestão.

Observou-se uma heterogeneidade na composição das grades curriculares nos cursos investigados, no tocante às disciplinas relacionadas à gestão. Isso significa dizer, a título de exemplo, que algumas instituições oferecem apenas uma disciplina em seu currículo, enquanto outras disponibilizam um eixo curricular formado por quatro ou até cinco disciplinas, incluindo a possibilidade de estágio na área de gestão.

A disposição ou configuração das disciplinas nas grades curriculares também é variada. Assim, em determinadas instituições as disciplinas relacionadas à gestão estão dispostas nas fases iniciais do curso, enquanto em outras as cadeiras de gestão estão alocadas na etapa final da formação.

A heterogeneidade de configuração das grades curriculares possibilita identificar que determinados cursos disponibilizam, por exemplo, três distintas disciplinas, sendo uma de "gestão esportiva", outra de "marketing esportivo" e mais uma de "empreendedorismo"; enquanto outros cursos disponibilizam os mesmos assuntos/conteúdos, porém em apenas uma disciplina intitulada "empreendedorismo, gestão e marketing esportivo". As cargas horárias das disciplinas também variam de uma instituição para outra.

Todos os currículos investigados (31 currículos) apresentaram pelo menos uma disciplina relacionada à gestão. A maioria das IES (17 das 31) proporciona mais de uma disciplina de gestão na formação em Educação Física, por outro lado, menos da metade (13 das 31) disponibiliza a possibilidade de estágios nessa área (estágio em gestão do esporte).

As disciplinas mais comumente observadas nos currículos dos cursos de bacharelado em Educação Física são vinculadas à gestão esportiva e à organização de eventos. As

Pensar a Prática, Goiânia, v. 17, n. 4, out./dez. 2014 
disciplinas com menor frequência nos currículos investigados são relativas ao marketing esportivo e a empreendedorismo.

Não obstante os resultados obtidos até então, a análise das disciplinas e de suas titulações demonstrou-se insuficiente ao perceber-se que disciplinas - de diferentes IES com denominações diferenciadas poderiam, por vezes, abordar temáticas semelhantes. E, ainda, que determinadas matérias poderiam explorar outros assuntos/temas além daqueles ao qual sua titulação remeteria inicialmente.

Nesse sentido, por meio da identificação de categorias temáticas presentes nas ementas das disciplinas já selecionadas, buscou-se compreender mais densamente a formação relacionada à gestão oferecida nos cursos de Educação Física.

\section{2- As ementas das disciplinas relacionadas à gestão}

A partir da análise de conteúdo identificaram-se categorias temáticas inseridas nos ementários das disciplinas relacionadas à gestão dos cursos investigados. O tema administração/gestão foi constantemente notado nos ementários das disciplinas e, por conseguinte, compuseram muitas das categorias identificadas - o que é compreensível visto que a análise incidiu sobre disciplinas relacionadas à gestão. Não obstante, outros assuntos foram observados nas ementas das disciplinas relacionando-se, direta ou indiretamente, à temática dominante.

Nas ementas das disciplinas relacionadas à gestão foram identificadas seis categorias temáticas: (1) Gestão de Organizações Esportivas; (2) Gestão e Empreendedorismo para Educação Física; (3) Organização de Eventos; (4) Marketing Esportivo; (5) Conhecimentos Intrínsecos à Gestão; e (6) Prática em Gestão.

Embora as categorias temáticas encontradas nos ementários das disciplinas possam assemelhar-se e até coincidir com categorias já identificadas nas nomenclaturas das disciplinas, é relevante destacar que as categorias advindas das ementas refletem efetivamente os assuntos, ou temas, contemplados pelas matérias acadêmicas da formação em Educação Física, independentemente da adequação das denominações dadas a elas pelas instituições de ensino.

Isso significa que um tema como o "marketing esportivo", por exemplo, pode ser observado em uma matéria com o mesmo nome, mas também pode estar presente em uma disciplina denominada "gestão esportiva", ou mesmo "organização de eventos".

Inicialmente, a "gestão esportiva" ou a Gestão de Organizações Esportivas foi identificada como uma categoria eminente nas ementas das disciplinas analisadas. Os ementários dessa categoria temática abordam essencialmente as teorias fundamentais da Administração aplicadas às organizações esportivas - clubes, academia, federações esportivas, etc. O planejamento estratégico, a elaboração de planos de negócios, as estruturas organizacionais e as principais funções administrativas (planejamento, organização, direção e controle) aplicadas à gestão de organizações esportivas, são alguns dos elementos identificados em ementas que compõem essa categoria temática.

De modo semelhante - mas não idêntico -, as teorias administrativas conjugadas à questão do empreendedorismo foram observadas relacionando-se à Educação Física como profissão, e, mais especificamente, aos profissionais da área. Nessa categoria, nomeada Gestão e Empreendedorismo para Educação Física, observaram-se ementas tra- 
tando de temas como estratégias de sucesso profissional; campo de atuação, mercado de trabalho e áreas emergentes da profissão; oportunidades de negócio, visão empreendedora, criatividade e casos de sucesso/fracasso em setores relacionados à Educação Física (esportes, fitness, saúde, lazer, etc.) e seus profissionais.

A Organização de Eventos surgiu, também, como outra categoria temática em evidência nas ementas das disciplinas relacionadas à gestão. Os ementários enquadrados nessa categoria versam essencialmente sobre a gestão de eventos e atividades relacionadas às áreas da Educação Física e esportiva - competições, campeonatos, torneios, gincanas, festivais esportivos; eventos comunitários e de lazer em geral. Temas como planejamento, organização, execução e avaliação de eventos/atividades diversos; os modelos e sistemas de disputa utilizados em competições esportivas e a elaboração de regulamentos; assim como os aspectos financeiros, de busca de patrocínios e de divulgação dos eventos, foram temas componentes desta categoria.

O Marketing Esportivo recebeu destaque e também foi percebido como um tema relevante à temática deste estudo. Nessa categoria, observou-se o marketing de organizações esportivas, incluindo os temas composto mercadológico, desenvolvimento de marcas, produtos e serviços, comportamento do consumidor, pesquisa de marketing, análise dos ciclos de vida de produtos e organizações sempre aplicados às organizações esportivas. Além desses, o marketing realizado por meio do esporte ou da indústria esportiva de suas organizações, produtos e serviços - e explorado, principalmente, na questão do patrocínio esportivo, também foi um tema identificado nessa categoria.

Percebeu-se que em determinadas ementas de disciplinas cuja temática central é a gestão, puderam ser observados elementos com íntima relação ao tema, mas que não se enquadrariam como teorias ou conhecimentos advindos da área administrativa. Assim, a legislação esportiva, por exemplo, foi um elemento observado em ementas de disciplinas ligadas à gestão, fazendo parte, portanto, de uma categoria nomeada Conhecimentos Intrínsecos à Gestão. Do mesmo modo, as políticas públicas e de incentivo ao esporte; as regulamentações vinculadas aos esportes e ao profissional da Educação Física; a legislação empresarial; a economia e a tecnologia vinculadas à indústria esportiva são abordagens que compuseram a categoria temática.

Esses componentes das ementas de gestão, mesmo não sendo compreendidas, em suas essências, como conhecimentos administrativos, fazem parte de um conjunto de saberes importantes à atuação na gestão esportiva e que embasam o trabalho nesse campo de atuação profissional (NOLASCO, 2006; FERRAZ et al., 2010). Fazem parte dos conhecimentos afeitos à área da gestão do esporte e, dessa forma, é compreensível que estejam presentes nas ementas das matérias acadêmicas concomitantemente aos fundamentos da administração, contribuindo e dando suporte à futura intervenção profissional, no âmbito da gestão.

Por fim, a Prática em Gestão foi identificada, basicamente, vinculada aos estágios dos cursos, mas também foi possível percebê-la em disciplinas - em princípio - não práticas, mas que propunham em seus ementários vivências pautadas na efetiva organização e realização de eventos, atividades recreativas ou competições esportivas.

Em relação aos estágios obrigatórios, destaca-se que ao analisar os ementários das disciplinas identificou-se que sua realização não era obrigatoriamente exercida na área da ges-

Pensar a Prática, Goiânia, v. 17, n. 4, out./dez. 2014 
tão, sendo apenas uma possibilidade, como pode ser percebido no seguinte texto de uma ementa de estágio obrigatório:

Estágio de prática profissional em Educação Física, sob orientação e supervisão docente, em instituições esportivas e/ou gestão dos esportes (Ementa de uma disciplina de estágio obrigatório - grifo nosso).

Não contraditoriamente ao já exposto sobre estágios, das 13 instituições que possibilitavam o estágio no âmbito da gestão esportiva, apenas uma das IES investigadas exigia, obrigatoriamente, um estágio nessa área. Nas outras instituições, o estágio em gestão do esporte era apenas uma possibilidade, podendo ser substituído por estágios em outras áreas, como treinamento, por exemplo.

O Quadro 1 sintetiza as categorias temáticas identificadas a partir das ementas das disciplinas analisadas e alguns de seus temas/assuntos componentes.

Pensar a Prática, Goiânia, v. 17, n. 4, out./dez. 2014 
Quadro 1. Categorias temáticas encontradas a partir das ementas das disciplinas relacionadas à gestão nos cursos de Educação Física.

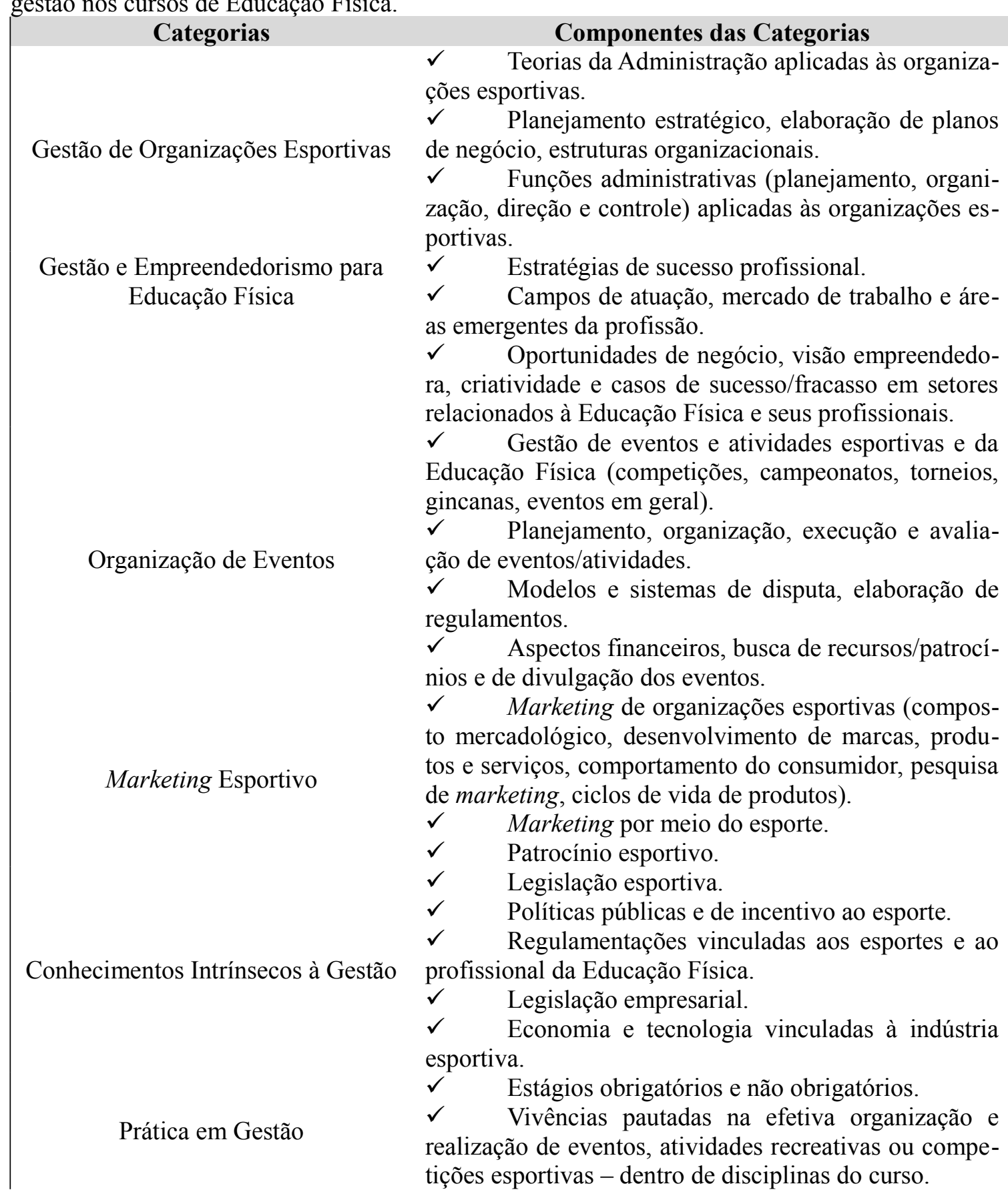

Fonte: Elaborado pelos próprios autores, 2014.

\section{3- Discussão dos resultados}

A formação em Educação Física relacionada à gestão, ao que aparenta, foi objeto de escassas investigações científicas que, como já mencionado, utilizaram-se de aborda- 
gens quantitativas em suas investidas empíricas. Não obstante essa constatação, os resultados do presente artigo não encontraram desarmonia entre os achados quantitativos das referidas investigações.

O estudo de Montagner, Scaglia e Amaya (2012), demonstrou que os currículos de graduação de cursos de Educação Física apresentam-se de maneira heterogênea em suas composições no tocante à gestão e que a totalidade das instituições de ensino públicas investigadas - federais e estaduais - oferece pelo menos uma disciplina relacionada à gestão em cursos de bacharelado em Educação Física. Tais constatações são corroboradas pelos resultados do presente estudo.

A abordagem quantitativa da pesquisa de Montagner, Scaglia e Amaya (2012) evidenciou, ainda, que a porcentagem da carga horária ocupada pelas disciplinas de gestão em relação à carga horária total dos cursos varia de $0,9 \%$ a $8,4 \%$, demonstrando novamente que a formação se apresenta de modo heterogêneo nas variadas instituições de ensino investigadas.

A pesquisa de Benfica et al. (2011), realizada em 169 instituições de ensino da Região Sudeste do Brasil, demonstrou, por outro lado, que nem todos os currículos dos cursos de graduação da região ofereciam disciplinas de gestão. Nos estados de Minas Gerais, São Paulo, Rio de Janeiro e Espírito Santo, respectivamente 98\%, 89\%, 86\% e 100\% das instituições de ensino oferecem disciplinas relacionadas à gestão em cursos de formação em Educação Física.

Oliveira (2008) havia investigado, especificamente, as instituições de ensino do estado do Espírito Santo e, ao contrário da pesquisa de Benfica et al. (2011), observou que somente 9 das 11 instituições investigadas (81\%) ofereciam disciplinas de gestão esportiva nos currículos de seus cursos. Na pesquisa, que também entrevistou coordenadores dos cursos de Educação Física, o autor constatou que as disciplinas de gestão eram consideradas importantes para a formação dos futuros profissionais, no entanto, essa perspectiva não era unanimidade entre os coordenadores dos cursos (OLIVEIRA, 2008).

Em pesquisa realizada na região da grande São Paulo, Barhum (2001 apud MAZZEI; AMAYA; BASTOS, 2013) concluiu, em conformidade aos resultados do presente estudo, que não existe modelo único em relação às disciplinas de gestão ofertadas, carga horária e conteúdos explorados.

Considerando o exposto até aqui e consciente que não existe no país uma diretriz curricular para a formação nessa área do conhecimento, é cabível observar algumas das recomendações encontradas para a formação de gestores esportivos em outros países, como, por exemplo, nos EUA.

No território americano, a COSMA (Commission on Sport Management Accreditation), responsável por normatizar e atualizar diretrizes para a formação de gestores esportivos no país indica que as seguintes áreas sejam contempladas, na formação de gestores esportivos, em nível de graduação (COSMA, 2010):

$\checkmark$ Fundamentos sociais, psicológicos e internacionais de gestão esportiva (princípios de gestão do esporte; liderança no esporte; gestão de eventos/operações e gestão do local; governança no esporte).

$\checkmark$ Ética na gestão do esporte.

$\checkmark$ Marketing esportivo e comunicação.

Pensar a Prática, Goiânia, v. 17, n. 4, out./dez. 2014 
$\checkmark$ Finanças/Contabilidade/Economia (princípios aplicados ao esporte).

$\checkmark$ Aspectos jurídicos/legais do esporte.

$\checkmark$ Experiência integrativa (gestão estratégica/política; estágio; experiências que permitam demonstrar a capacidade de sintetizar e aplicar o conhecimento, como uma tese, projeto, exame).

Enfatiza-se - ainda em tempo - que, tendo em vista todo o debate envolvido neste estudo e considerando a importância de o currículo de formação do gestor esportivo levar em conta as distintas demandas internacionais da área (HAAN; SHERRY, 2012), mas acreditando, também, na consideração e no respeito às especificidades e demandas nacionais e regionais, entende-se que as diretrizes americanas, combinadas aos vários estudos/argumentos aqui apresentados, podem contribuir para a formação de profissionais de Educação Física com um perfil voltado - também - para a gestão de organizações es portivas.

Desse modo, destaca-se, novamente, que a formação oferecida em cursos de graduação em Educação Física, mesmo estabelecendo - certas vezes - alguma relação com aspectos de gestão, não deve ser confundida com a formação específica de gestores esportivos. Isso porque um curso de formação em Educação Física não forma gestores esportivos - forma profissionais de Educação Física -, e a gestão do esporte é apenas uma das áreas de intervenção que o referido profissional pode atuar.

A gestão deve ser considerada, sim, como um componente relevante na formação profissional na área, mas não o ingrediente principal. Enfatizar demasiadamente os conteúdos de gestão em um curso de graduação faria com que fosse formado um gestor esportivo e não um profissional de Educação Física. Não obstante essa percepção, compreende-se que as diretrizes de formação de gestores esportivos podem, sim, contribuir para a formação no campo da Educação Física.

\section{4- Considerações finais}

Em consonância com pesquisas já publicadas observou-se que a formação oferecida em cursos de Educação Física - no que se relaciona à temática da gestão - é explorada de maneira variada e heterogênea em diversos aspectos observados.

Existe uma ampla variedade de configurações curriculares nos cursos investigados, no que tange à quantidade de disciplinas que são oferecidas durante a formação. Essa variedade é, também, observada nas terminologias utilizadas para nomear as disciplinas e, igualmente, na disposição das matérias acadêmicas ao longo dos semestres dos currículos. Os próprios temas/assuntos que são tratados por várias disciplinas em alguns cursos, são abordados, por vezes, em uma única disciplina em outras instituições de ensino, o que demonstra a heterogeneidade do processo formativo na Educação Física.

A partir da análise do escopo e das titulações das disciplinas observadas, foram identificadas cinco categorias relacionadas à área da gestão: (1) Gestão Esportiva, (2) Organização de Eventos, (3) Marketing Esportivo, (4) Empreendedorismo e (5) Estágio em Gestão; e da análise dos ementários dessas mesmas matérias advieram seis categorias temáticas: (1) Gestão de Organizações Esportivas; (2) Gestão e Empreendedorismo para 
Educação Física; (3) Organização de Eventos; (4) Marketing Esportivo; (5) Conhecimentos Intrínsecos à Gestão e (6) Prática em Gestão.

É válido destacar que embora o conjunto de disciplinas e ementas analisadas tenha abrangido um escopo de conhecimentos e temas amplo, tal conclusão não necessariamente condiz com a realidade individual dos cursos de formação, e sim com análise realizada sob o conjunto das instituições de ensino. Isso significa que o conjunto de temáticas identificadas aborda elementos em harmonia com as necessidades de conhecimentos/habilidades referidos na literatura sobre a atuação de gestores esportivos, todavia tais temas não necessariamente são contemplados em todas as grades curriculares e ementas dos cursos de formação.

É razoável afirmar que não existe uma configuração curricular correta ou incorreta no que tange às matérias de gestão. Afinal, as arquiteturas curriculares devem estar de acordo com o perfil do profissional de Educação Física que se deseja formar em cada curso. Essa formação pode, ou não, contemplar ingredientes relacionados à gestão, mas o perfil profissiográfico - do formando na área - deve atender às demandas do contexto social ao qual a instituição de ensino atende.

Caso seja desejável que o futuro profissional esteja capacitado a atuar na gestão de uma organização esportiva, é importante que a formação - independentemente da quantidade de disciplinas, da carga horária oferecida e da nomenclatura das matérias proporcione fundamentos, possibilite e/ou estimule o desenvolvimento das competências necessárias para tal função.

Ainda em tempo, cabe inferir que, se a gestão de organizações esportivas é uma possibilidade de intervenção do profissional de Educação Física, a formação profissional nessa área deve considerar a gestão e os conhecimentos administrativos como componentes relevantes em seu corpo de matérias curriculares. A gestão como temática explorada em cursos de formação em Educação Física é importante e justificada pela necessidade de se ter administradores esportivos mais bem preparados no país. Mesmo que não se tornem gestores esportivos, profissionais de Educação Física podem se beneficiar dos fundamentos administrativos adquiridos durante o curso universitário.

Por fim, entende-se que a atual conjuntura da gestão esportiva brasileira não pode simplesmente ser relacionada à formação de gestores esportivos advindos de cursos de Educação Física. Não obstante, acredita-se que cursos de Educação Física podem contribuir para a melhoria da qualificação profissional de seus egressos no tocante à gestão. Aperfeiçoando a formação relacionada à gestão estarão contribuindo para a formação de profissionais de Educação Física mais bem preparados e para o desenvolvimento da gestão do esporte no contexto nacional.

Uma formação de alta qualidade, bem planejada e fundamentada em objetivos que atendam efetivamente às demandas da sociedade é o alicerce fundamental para a superação das deficiências que o país apresenta. A gestão do esporte brasileiro é uma área que necessita evoluir profissional e academicamente, e a área da Educação Física pode contribuir para esse desenvolvimento.

Pensar a Prática, Goiânia, v. 17, n. 4, out./dez. 2014 


\title{
TRAINING RELATED TO THE MANAGEMENT OFFERED IN UNDERGRADUATE COURSES ON PHYSICAL EDUCATION: A QUALITATIVE VIEW ON CURRICULA, SUBJECTS AND SUMMARIES
}

\begin{abstract}
The aim of this qualitative and descriptive study was to assess training related to management and offered in undergraduate courses on Physical Education. It was possible to perform documental analysis of curricula, subjects and summaries about management on Bachelor Degree courses of the area, in the state of Santa Catarina. Results point out thematic categories identified in the subjects and summaries, and they demonstrate that the training is presented heterogeneously in courses investigated. The conclusion was that management contents are necessary for Physical Education training, and schools should consider such contents as essential training components because sports management is an intervention possibility of a future professional in the area.

Keywords: Training. Sports manager. Sport management. Physical Education.

\section{FORMACIÓN RELACIONADA CON LA GESTIÓN OFRECIDA EN CURSOS DE GRADUACIÓN EN EDUCACIÓN FÍSICA: UNA MIRADA CUALITATIVA SOBRE CURRÍCULOS, DISCIPLINAS Y ENMIENDAS}

\section{Resumen}

El objetivo de este estudio cualitativo y descriptivo fue el de analizar la formación relacionada con la administración ofrecida en los cursos de graduación en Educación Física. Se realizó un análisis documental de currículos, materias y enmiendas de las asignaturas relacionadas con la gestión de los cursos de licenciatura del área, en el estado de Santa Catarina. Los resultados muestran categorías temáticas identificadas en las materias y enmiendas, y demuestran que la formación se presenta de forma heterogénea en los cursos investigados. Se concluye que los contenidos de la gestión son importantes para la formación en Educación Física y que las instituciones de enseñanza deben considerar tales contenidos como componentes fundamentales de esa formación, ya que la administración del deporte es considerada como una posibilidad de intervención del futuro profesional en esa área.

Palabras clave: Formación. Gestor deportivo. Gestión del deporte. Educación Física.

\section{Referências}

AZEVEDO, P. H. O esporte como negócio: uma visão sobre a gestão do esporte nos dias atuais. Revista Estudos, Goiânia, v. 36, n. 9/10, p. 929-939, set./out. 2009.

AZEVÊDO, P. H.; BARROS, J.F. A necessidade de administração profissional do esporte brasileiro e o perfil do gestor público, em nível federal, que atuou de 1995 a 2002. Lecturas, Educación Física y Deportes - Revista Digital, Buenos Aires, v.10, n.74, 2004. Disponível em: <http://www.efdeportes.com>. Acesso em: 15 jul. 2012.

AZEVÊDO, P.H.; BARROS, J.S.; SUAIDEN, S. Caracterização do perfil do gestor esportivo dos clubes da primeira divisão de futebol do Distrito Federal e suas relações com 
a legislação esportiva brasileira. Revista da Educação Física/UEM,v.15, n. 1, p. 33-42, 2004.

BARDIN, L. Análise de conteúdo. Lisboa: Editora 70, 2004.

BASTOS, F.C. Administração esportiva: área de estudo, pesquisa e perspectivas no Brasil. Motrivivência, São Cristóvão, v.15, n.20/21, p.295-306, 2003.

BASTOS, F.C.; BARHUM, R.; ALVES, M.; BASTOS, E.; MATTAR, M.; REZENDE, M.; MARDEGAN, M.; BELLANGERO, D. Perfil do administrador esportivo de clubes de São Paulo/Brasil. Revista Mackenzie de Educação Física e Esporte, São Paulo, v. 5, n. 1, p. 13-22, 2006.

BASTOS, F.C.; MAZZEI, L.C. Gestão do esporte no Brasil: desafios e perspectivas. In: MAZZEI, L.C.; BASTOS, F.C. (Org.). Gestão do esporte no Brasil: desafios e perspectivas. São Paulo: Ícone, 2012.

BENFICA et al. A oferta de disciplinas relacionadas à gestão esportiva nas instituições de ensino superior da Região Sudeste. In: CONGRESSO INTERNACIONAL SOBRE GESTÃO DO ESPORTE, 1.,e CONGRESSO BRASILEIRO SOBRE GESTÃO DO ESPORTE, 4., 2011. Anais... Brasília, 2011.

CAPINUSSÚ, J. M. Administração desportiva moderna. São Paulo: Ibrasa, 2002.

CELLARD, A. A análise documental. In: POUPART, J. et al. A pesquisa qualitativa: enfoques epistemológicos e metodológicos. Petrópolis: Vozes, 2008. p.295-316.

COMMISSION ON SPORT MANAGEMENT ACCREDITATION (COSMA). Accreditation principles \&self study preparation.Revised June 2010. Disponível em: $<$ http://cosmaweb.org/sites/all/pdf_files/COSMA_Accreditation_principles.pdf $>$. Acesso em: 10 jan. 2013.

CONSELHO FEDERAL DE EDUCAÇÃO FÍSICA (CONFEF). Documento de intervenção do profissional de Educação Física. Rio de janeiro: CONFEF, 2002.

COSTA, F. L.; MARINHO, E. Fome de bola: o futebol no Brasil e os desafios da gestão esportiva. Revista Portuguesa e Brasileira de Gestão, Lisboa, v. 4, n. 1, p.15, 2005.

FERRAZ,T. M.; LOPES, P. C.; TEOTÔNIO, A. C.; BORRAGINE, S. O. F. Gestão esportiva: competências e qualificações do profissional de Educação Física. Lecturas, Educación Física y Deportes-Revista Digital, Buenos Aires, año 15, n. 147, 2010. Disponível em: <www.efdeportes.com>. Acesso em: 20 jun. 2011.

GIL, A.C. Métodos e técnicas de pesquisa social. 6. ed. São Paulo: Atlas, 2008. 
HAAN, D.; SHERRY, E. Internationalisation of the sport management curriculum academic and student reflections. Journal of Studies in International Education, v. 16, n. 1, p. 24-39, feb. 2012. Disponível em: <http://jsi.sagepub.com/content/16/1/24>. Acesso em: 10 out. 2013.

MACIEL, M. G. Perfil do gestor de lazer nas empresas. Revista Brasileira de Ciências do Esporte, Campinas, v. 31, n. 1, p. 57-73, 2009.

MARONI, F. C.; MENDES, D. R.; BASTOS, F. C. Gestão do voleibol no Brasil: o caso das equipes participantes da Superliga 2007-2008. Revista Brasileira de Educação Física e Esporte, São Paulo, v. 24, n. 2, p.239-248, 2010.

MAZZEI, L.C.; AMAYA, K.; BASTOS, F.C. Programas acadêmicos de graduação em gestão do esporte no Brasil. Revista Mackenzie de Educação Física e Esporte (Online), v. 12, n. 1, p. 219-234, 2013. Disponível em: <http://editorarevistas.mackenzie.br/index.php/remef/article/view/4458>. Acesso em: 29 dez. 2014.

MONTAGNER, P. C.; SCAGLIA, A. J.; AMAYA, K. G. Desafios da formação em esporte para intervenção profissional no contexto da gestão: investigações iniciais. In: NASCIMENTO, J. V.; FARIAS, G. O. (Org.). Construção da identidade profissional em Educação Física: da formação à intervenção. Florianópolis: UDESC, 2012.

NOLASCO, V. P. Administração/gestão esportiva. In: COSTA, L. P. (Org.). Atlas do esporte no Brasil: atlas do esporte, educação física e atividades físicas de saúde e lazer no Brasil. Rio de Janeiro: Shape, 2006.p. 760-761.

OLIVEIRA, R.J.S. Gestão esportiva: um estudo de caso nas instituições de ensino superior dos cursos de Educação Física do estado do Espírito Santo. 2008. Dissertação (Mestrado em Ciências do Desporto) -Universidade do Porto, 2008.

RICHARDSON, R.J.; PERES, J.A.S.; WANDERLEY, J.C.V.; CORREIA, L.M.; PERES, M.H.M. Pesquisa social: métodos e técnicas. 3. ed. São Paulo: Atlas, 2007.

VALENTE, R.; SERAFIM, M. Gestão esportiva: novos rumos para o futebol brasileiro. Revista de Administração de Empresas, Rio de Janeiro, v. 46, n. 3, p. 131-136, 2006.

VIEIRA, T. P.; STUCCHI, S. Relações preliminares entre a gestão esportiva e o profissional de Educação Física. Revista Conexões, Campinas, v. 5, n. 2, p. 113-128, 2007.

Recebido em: $15 / 05 / 2014$

Revisado em: 15/07/2014

Aprovado em: 26/09/2014

Pensar a Prática, Goiânia, v. 17, n. 4, out./dez. 2014 
Endereço para correspondência:

alfredorcardenas@hotmail.com

Alfredo Ribeiro Cárdenas

Universidade do Estado de Santa Catarina, Centro de Ciências da Administração e Sócio Econômicas - ESAG.

Av. Madre Benvenuta, 2037

Itacorubi

88035001 - Florianópolis, SC - Brasil

Pensar a Prática, Goiânia, v. 17, n. 4, out./dez. 2014 